\title{
AVALIAÇÃO DO COMPORTAMENTO MECÂNICO DE JUNTAS PARAFUSADAS ATRAVÉS DE SIMULAÇÃO NUMÉRICA*
}

Raphael Calazans Cardoso ${ }^{1}$ Felipe de Freitas Thompson² Sandro Griza ${ }^{3}$

\section{Resumo}

Os procedimentos de dimensionamento de juntas parafusadas devem corresponder adequadamente às condições impostas na prática, para garantir projetos de alta confiabilidade. Por isso, este estudo tem o objetivo de evoluir na compreensão do comportamento mecânico de juntas parafusadas submetidas à carga axial externa. Para tal foram realizadas simulações numéricas variando a pré-carga de aperto, o comprimento do parafuso, o atrito entre os componentes, a posição de aplicação da carga externa e os materiais dos membros apertados, de modo a verificar a parcela da carga externa transferida ao parafuso. Todos os fatores analisados alteram 0 comportamento mecânico da junta, exceto 0 atrito entre os componentes. A transmissão da carga ao parafuso se comporta de maneira não-linear pelo aumento da carga externa. Além disso, existe um patamar de carga externa abaixo do qual não há transferência de carga ao parafuso.

Palavras-chave:Juntas parafusadas; Comportamento mecânico; Simulação numérica.

\section{EVALUATION OF MECHANICAL BEHAVIOR OF BOLTED JOINTS USING NUMERICAL SIMULATION}

\section{Abstract}

The procedures of bolted joints design must correspond appropriately with real conditions, to ensure projects of high reliability. Therefore, this study aims to evolve the understanding of the mechanical behavior of bolted joints subjected to the external axial load. For this, finite element analysis were performed, varying the preload of tightening, the length of the bolt, the factor of friction between the components, the position of application of the external load and the materials of the tightened members, in order to verify a portion of the external load transferred to bolt. All factors analyzed modify the mechanical behavior of the joint, except the friction between the components. The transmission of the load to the bolt behaves in a nonlinear manner by increasing the external load. In addition, there is an external load landing below which there is no load transfer to the bolt.

Keywords: Bolted joints; Mechanical behavior; Numerical simulation.

1 Engenheiro Mecânico, Mestrando,Programa de Pós-Graduação em Ciência e Engenharia de Materiais (P2CEM), Universidade Federal de Sergipe, São Cristóvão, Sergipe e Brasil.

2 Engenheiro Mecânico, Mestre,Programa de Pós-Graduação em Ciência e Engenharia de Materiais (P2CEM), Universidade Federal de Sergipe, São Cristóvão, Sergipe e Brasil.

3 Engenheiro Mecânico, Doutor, Professor, Programa de Pós-Graduação em Ciência e Engenharia de Materiais (P2CEM), Universidade Federal de Sergipe, São Cristóvão, Sergipe e Brasil. 


\section{INTRODUÇÃO}

Juntas parafusadas possuem importante papel como elementos de fixação em projetos de engenharia de alta responsabilidade [1]. Tais juntas poderiam ser projetadas de forma mais confiável para garantir a integridade estrutural dos sistemas mecânicos permitindo o uso de parafusos de menor bitola possível, o que resultaria em economia de recursos.

De acordo com procedimentos convencionais de projetos de juntas parafusadas [1,2], os parafusos devem ser fixados aplicando-se um carregamento inicial (pré-carga) de $90 \%$ da tensão ao escoamento do material do parafuso, no caso de uniões permanentes, através da aplicação de um torque na porca. Esse procedimento é realizado com o intuito de prevenir a soltura da porca durante cargas cíclicas externas e melhorar a resistência da junta [3].

Uma porção da carga externa é absorvida pelo parafuso e outra pelos membros (aqui definidos como as peças que serão montadas), sendo a rigidez desses elementos um fator que determina a porção da carga que será distribuída para cada um dos elementos [1]. Deste modo, a determinação exata dos valores de rigidez é importante para o conhecimento da resistência da junta. Contudo, é observado que os procedimentos convencionais de dimensionamento de juntas parafusadas tendem a superestimar a carga transferida ao parafuso, acarretando a execução de projetos de elevados coeficientes de segurança [4,5]. 0 superdimensionamento de parafusos constitui-se em gastos adicionais de material que poderiam ser evitados.

A limitação dos procedimentos convencionais de cálculo consiste na consideração de que os componentes da junta possuem comportamento linear elástico (modelo de "molas") quando da aplicação da carga externa [6], de maneira que desconsideram possíveis não linearidades do comportamento mecânico da junta parafusada. Por isso que ao longo do tempo, diversos modelos $[5,7,8,9]$ foram propostos para o cálculo da rigidez dos componentes, a fim de se encontrar 0 modelo que represente de forma mais adequada a rigidez da junta e as não linearidades desta em função dos carregamentos, permitindo a previsão mais exata possível do carregamento imposto ao parafuso.

Desta forma, o presente estudo tem por objetivo evoluir na compreensão do comportamento mecânico de juntas parafusadas submetidas à carga externa axial por meio da observação da variação de parâmetros da junta em função da transferência de carga ao parafuso através de simulação numérica.

\section{MATERIAIS E MÉTODOS}

O desenvolvimento do estudo foi baseado em uma junta parafusada padrão de parafuso M8 x 1,25 classe 8.8 e membros com diâmetro externo de 104 mm, como representado na Figura 1. 


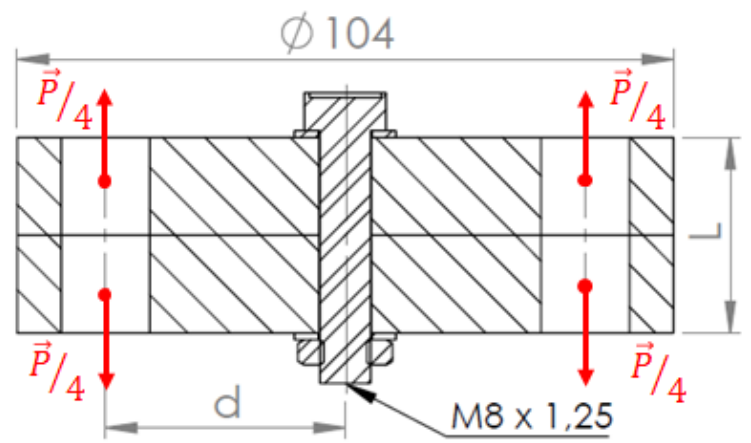

Figura 1 - Representação da junta parafusada padrão utilizada como objeto de estudo.

\subsection{Simulação numérica}

\subsubsection{Modelagem}

Os sólidos foram desenvolvidos em software CAD e, posteriormente foram importados para o software CAE Abaqus ${ }^{\circledR}$ 6.13. para realização das simulações numéricas. As simulações foram do tipo linear estática-estrutural, de maneira que foram inseridas as características de cada junta: materiais, interações, condições de contorno e carregamento. A modelagem das roscas foi realizada através da confecção de dois corpos, um liso e outro contendo os filetes da rosca. Então, a interação de contato sem graus de liberdade (superfícies coladas) foi estabelecida entre eles. Esta técnica está ilustrada na figura 2. Este artifício foi utilizado por causa da dificuldade de estabelecer a malha de forma adequada para o caso do parafuso de corpo único contendo a geometria helicoidal dos filetes.
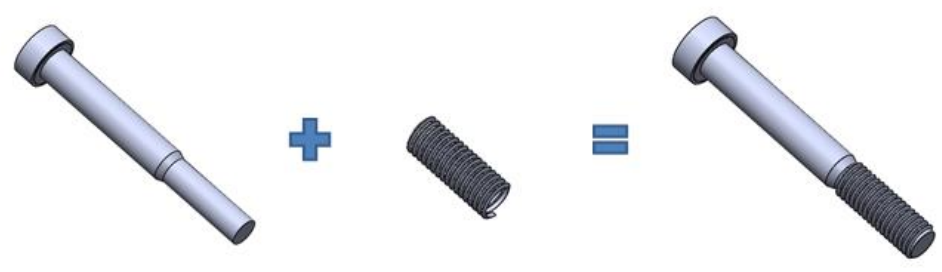

Figura 2 - Artifício para modelagem da geometria rosqueada.

\subsubsection{Geração da malha}

A malha desenvolvida para os modelos pode ser visualizada na figura 3 . 0 elemento utilizado na geração da malha dos componentes foi do tipo "3D Stress" hexagonal com 8 nós. O tamanho médio do elemento foi de $3 \mathrm{~mm}$ para os membros e de $0,4 \mathrm{~mm}$ para os demais componentes. 


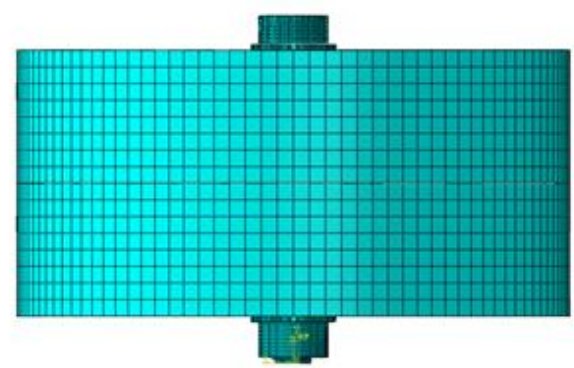

a)

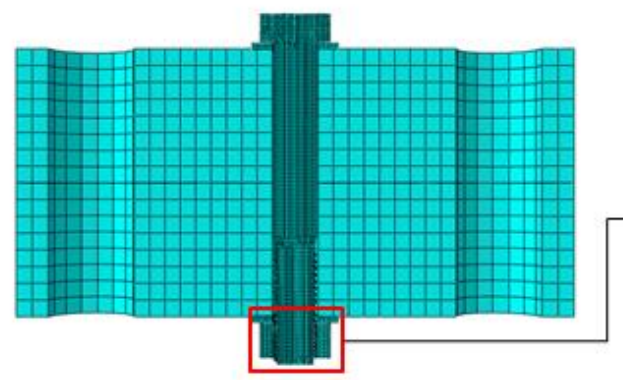

c)

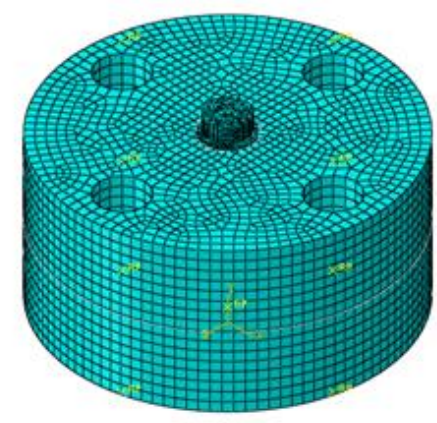

b)

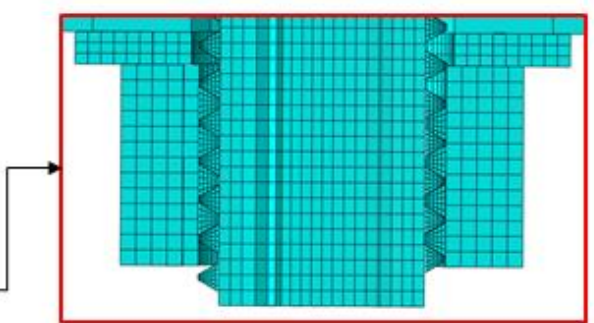

d)

Figura 3 - As figuras a), b), c) e d) representam a malha do modelo em vista frontal, isométrica, em corte e em detalhe das roscas, respectivamente.

\subsubsection{Condições de contorno}

No primeiro momento da simulação é aplicado o torque de pré-carga na junta parafusada através da fixação da cabeça do parafuso e da rotação da porca no sentido horário, até que seja aplicada a pré-carga desejada. No segundo momento é desativada a fixação na cabeça do parafuso e aplicado um deslocamento em uma distância " $d$ " (como representado na figura 1) do centro de simetria do parafuso e a força de reação para tal deslocamento é registrada. Além disso, a força transmitida ao parafuso é obtida pela relação entre tensão principal observada na direção longitudinal na haste do parafuso pela sua respectiva área a cada incremento da simulação.

\subsection{Método}

A metodologia deste estudo consiste na análise do comportamento mecânico da junta parafusada de diferentes características através simulações numéricas. Os modelos foram desenvolvidos de modo a variar a pré-carga de aperto, 0 comprimento do parafuso, o fator de atrito entre os componentes, a posição de aplicação da carga externa e os materiais dos membros apertados. Deste modo, foram desenvolvidos 6 modelos, especificados na tabela 1.

O estudo foi conduzido de maneira que um parâmetro fosse modificado enquanto os demais fossem mantidos constantes, para avaliar seu efeito no comportamento mecânico da junta. Vale ressaltar que quando há substituição para o parafuso de maior comprimento, a espessura dos membros " $L$ " (representado na figura 1) também aumenta, de modo que para o parafuso de 60 e $80 \mathrm{~mm}$, a espessura vale 50 e $70 \mathrm{~mm}$, respectivamente. Além disso, os materiais dos membros são modificados pela alteração do módulo de elasticidade introduzido na 
simulação, de modo que para o aço e para o alumínio, o módulo de elasticidade utilizado foi $200 \mathrm{GPa}$ e $70 \mathrm{GPa}$, respectivamente.

Tabela 1 - Modelos de juntas parafusadas

\begin{tabular}{|c|c|c|c|c|c|}
\hline Parâmetro & $\begin{array}{c}\text { Pré-carga } \\
\text { (\% da tensão } \\
\text { de } \\
\text { escoamento) }\end{array}$ & $\begin{array}{c}\text { Comprimento do } \\
\text { parafuso (mm) }\end{array}$ & $\begin{array}{c}\text { Fator } \\
\text { de } \\
\text { atrito }\end{array}$ & $\begin{array}{l}\text { Posição da } \\
\text { carga } \\
\text { externa "d" } \\
\text { (mm) }\end{array}$ & $\begin{array}{c}\text { Materiais } \\
\text { dos } \\
\text { membros }\end{array}$ \\
\hline 1 & 60 & $60 \mathrm{~mm}$ & 0,10 & 38 & Aço \\
\hline 2 & 90 & $60 \mathrm{~mm}$ & 0,10 & 38 & Aço \\
\hline 3 & 90 & $60 \mathrm{~mm}$ & 0,20 & 38 & Aço \\
\hline 4 & 90 & $60 \mathrm{~mm}$ & 0,20 & 38 & Alumínio \\
\hline 5 & 90 & $80 \mathrm{~mm}$ & 0,10 & 38 & Aço \\
\hline 6 & 90 & $60 \mathrm{~mm}$ & 0,10 & 25 & Aço \\
\hline
\end{tabular}

\section{RESULTADOS E DISCUSSÃO}

\subsection{Comportamento mecânico não linear da junta parafusada}

O estudo mostrou que a carga total no parafuso não possui relação linear com a carga externa. Tal fenômeno está representado no gráfico da Figura 4 . 0 comportamento não linear apresentado pode ser analisado em três momentos quando da magnitude da carga externa.

No primeiro momento, quando a carga externa é relativamente baixa, não existe transmissão significativa de carga ao parafuso. A depender dos parâmetros da junta, nesse momento pode até haver um pequeno alívio de carga no parafuso. Tal fato é atribuído ao contato interno entre os membros [10]. Para avaliar esse fenômeno foi observada a pressão de contato no nó interno de um dos membros pelo aumento da carga externa (Figura 5). Há um leve aumento na pressão de contato em cargas externas baixas e em seguida a pressão é reduzida até zero quando da separação da junta.

No segundo momento, há a transmissão de carga ao parafuso. Este momento é de fundamental importância para o dimensionamento da junta, uma vez que através do conhecimento da carga externa aplicada na junta é possível predizer a carga que é absorvida pelo parafuso. Deste modo, a partir do conhecimento exato da carga transmitida ao parafuso é possível selecioná-lo da maneira mais adequada.

Por fim, no terceiro momento, a carga externa é tão alta que separa os membros apertados, e não há mais contato entre eles. No projeto de juntas parafusadas, essa situação deve ser evitada, uma vez que toda a carga externa é transferida ao parafuso e também porque provoca a perda de estanqueidade da junta.

Além disso, a introdução deste conceito de região de não transmissão de carga externa colabora para o entendimento da influência do limite de resistência à fadiga de juntas parafusadas. De acordo com os procedimentos convencionais de projeto de juntas [1,2], desde o primeiro momento de aplicação de carga externa na 
junta haverá a transmissão de carga ao parafuso. Como o parafuso já está prétensionado a $90 \%$ da tensão de escoamento (tensão média alta), qualquer parcela de carga alternante transmitida ao parafuso iria conduzi-lo à falha por fadiga. No entanto, em ensaios de fadiga realizados em juntas parafusadas $[3,11,12]$, foi observado que o limite de resistência à fadiga aumenta com o aumento da précarga, e o limite ocorre após o início de transmissão de carga externa indicado no comportamento mecânico proposto nesse estudo. Tal região de não transmissão de carga externa indica uma possível explicação para o limite de resistência à fadiga ocorrer em carregamentos elevados.

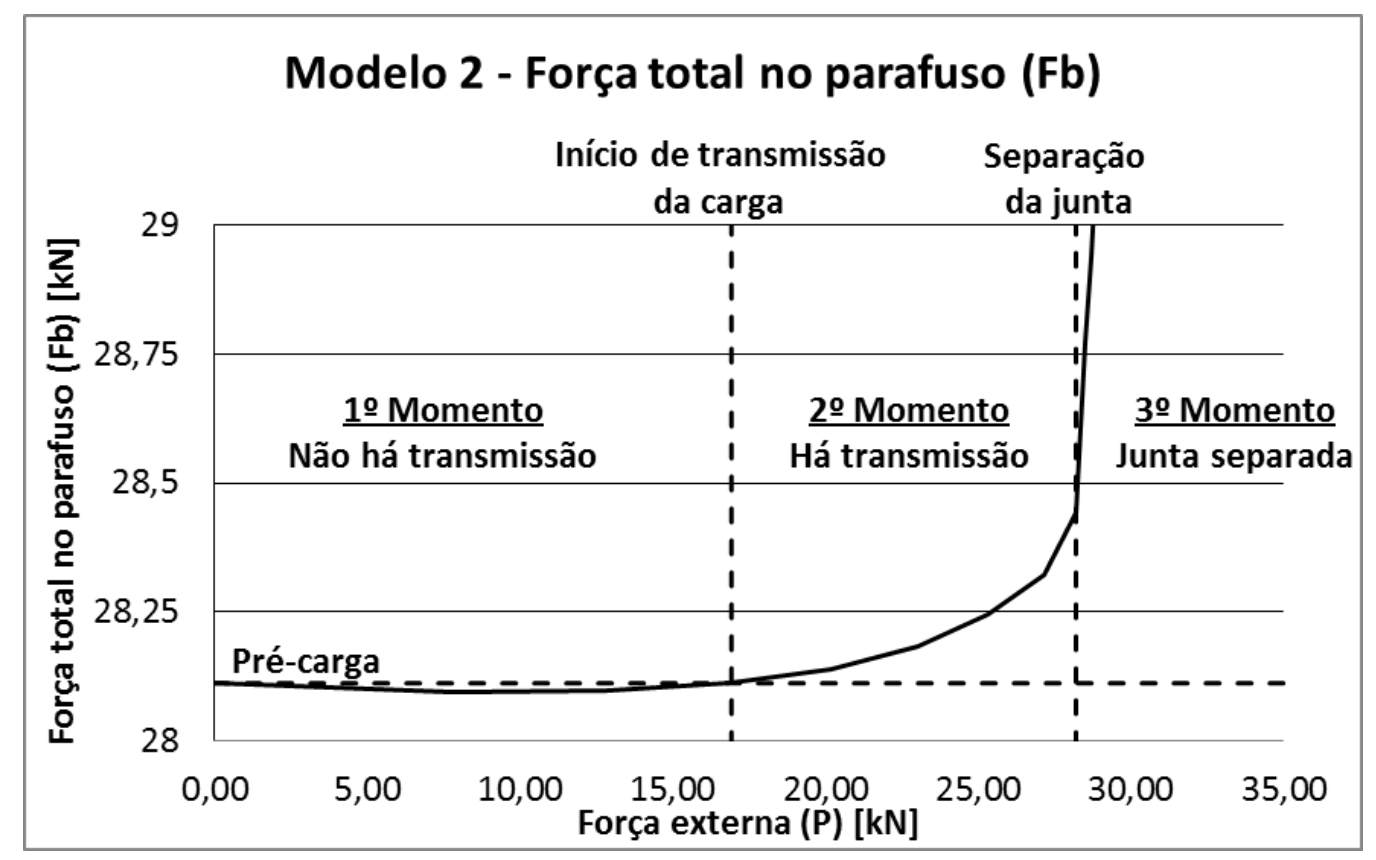

Figura 4 - Comportamento mecânico não linear de junta parafusada. Resultados extraídos do modelo 2.

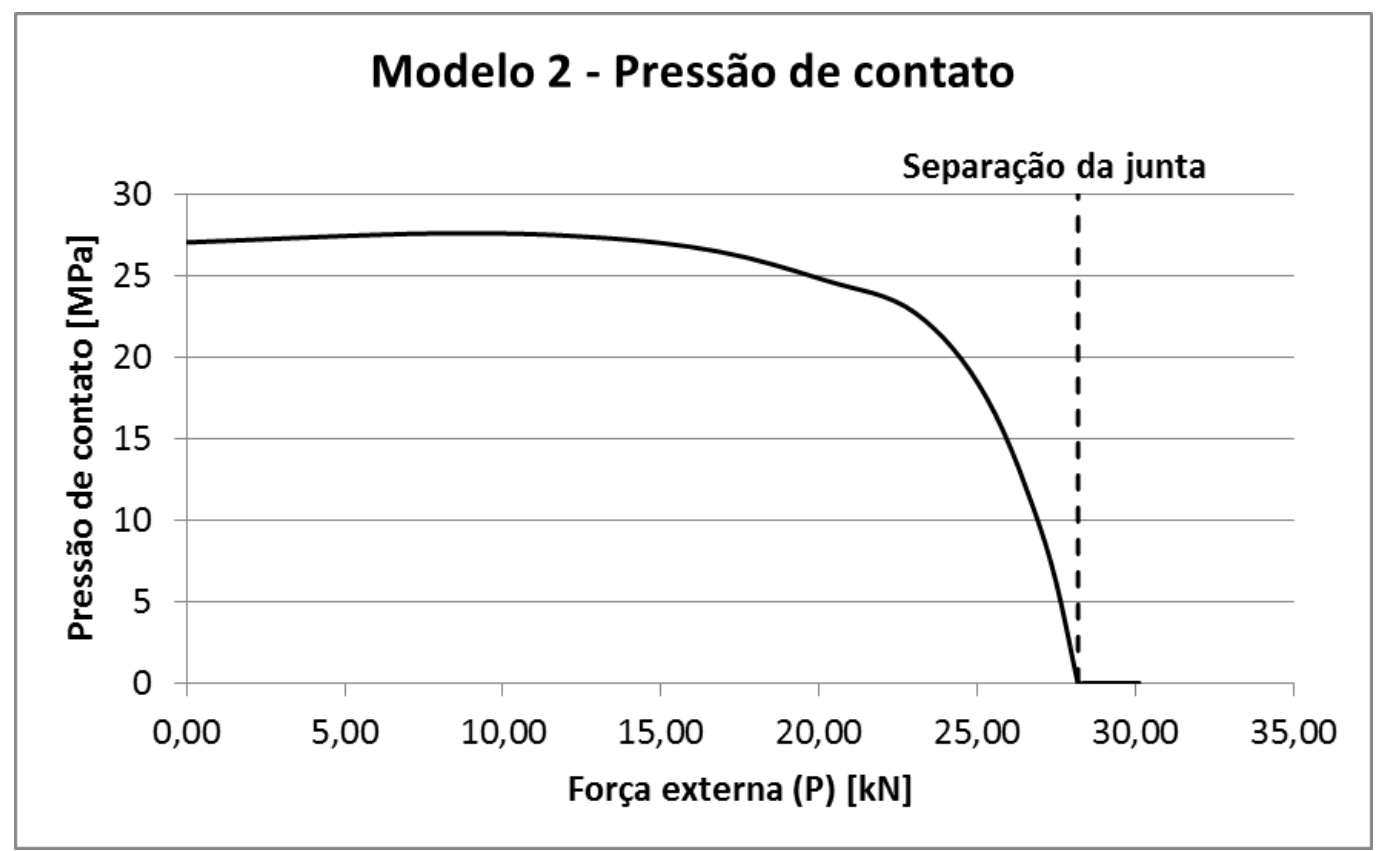

Figura 5 - Variação da pressão de contato no nó interno de um dos membros. 


\subsection{Efeito dos parâmetros da junta no comportamento mecânico}

A análise do efeito dos parâmetros da junta é realizada a partir dos gráficos de carregamento adimensional expostos nas Figuras 6 a 10. Inicialmente, foi observado que, para a maioria dos modelos, a separação da junta se dá quando a carga externa é igual à pré-carga $\left(P / P_{i}=1\right)$ ou um pouco superior. Além disso, os gráficos representam o carregamento externo adimensional a partir de 0,45 , uma vez que a parcela de carga transmitida ao parafuso é praticamente nula para carregamentos inferiores a esses.

A mudança no coeficiente de atrito entre os componentes não altera o comportamento mecânico da junta (Figura 6). Entretanto, deve-se ressaltar que quanto maior o atrito, é necessário um torque superior para aplicar a mesma précarga na junta [2]. Dessa forma, a determinação do coeficiente de atrito é importante para estimar o torque inicial para se aplicar a pré-carga desejada.

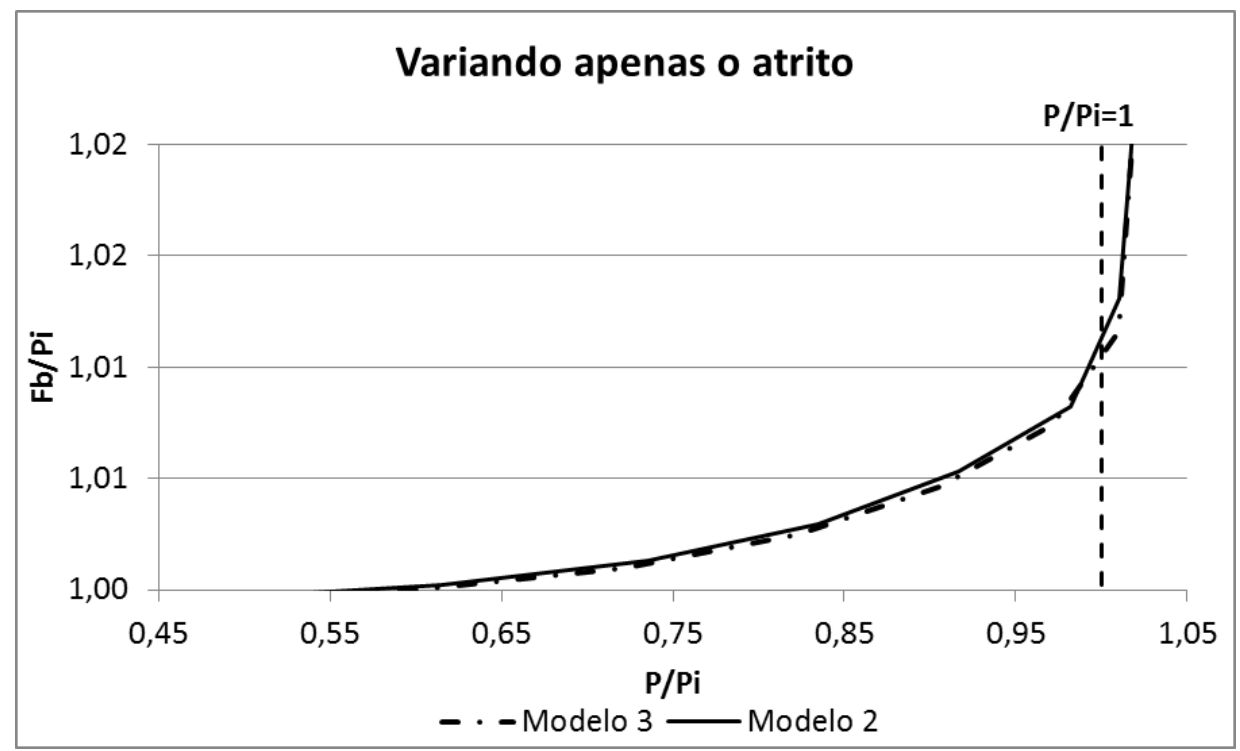

Figura 6 - Carregamentos adimensionais quando da variação apenas do atrito.

A Figura 7 mostra que o parafuso da junta com membros em alumínio absorve maior carga para uma mesma carga externa do que uma junta com membros em aço na zona de transmissão de carga. Portanto, para se atingir o limite de fadiga de juntas em aço é necessário realizar uma carga externa adicional, uma vez que uma parcela menor da carga externa é absorvida pelo parafuso. Tal fato poderia contrariar os resultados encontrados na literatura [3], que indicam que juntas com membros tanto em aço quanto em alumínio, possuem mesmo limite de fadiga. Porém, para que possuam o mesmo limite, as juntas de aço sofrem torque superior às de alumínio, o que explica a carga adicional necessária. 


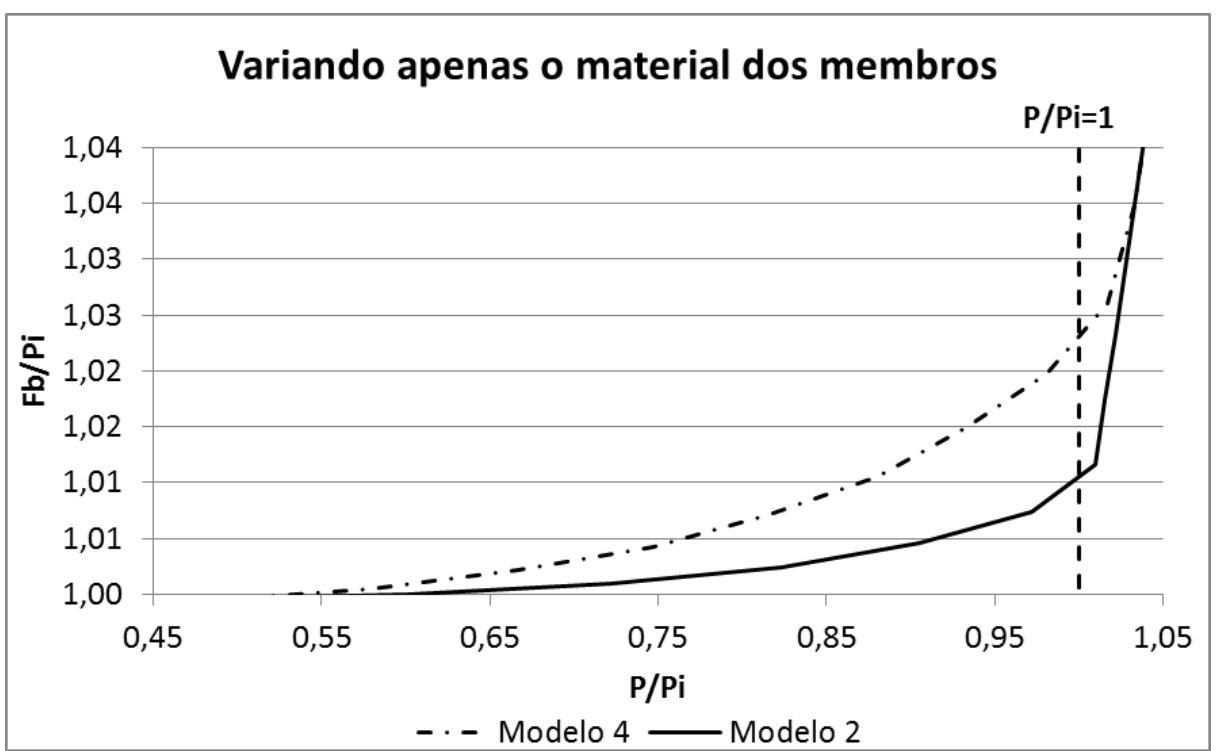

Figura 7 - Carregamentos adimensionais quando da variação apenas dos materiais dos membros.

A Figura 8 releva que quanto maior o comprimento do parafuso, menor será a parcela da carga externa absorvida pelo parafuso na região de transmissão de carga. Tal fato pode ser associado aos resultados obtidos em outros estudos $[11,12,13]$, os quais afirmam que a carga externa limite de fadiga é maior à medida que o comprimento do parafuso aumenta. Da mesma maneira que no caso anterior da variação dos materiais dos membros, parafuso de maior comprimento requer carga externa adicional para atingir a mesma carga transmitida ao parafuso de menor comprimento.

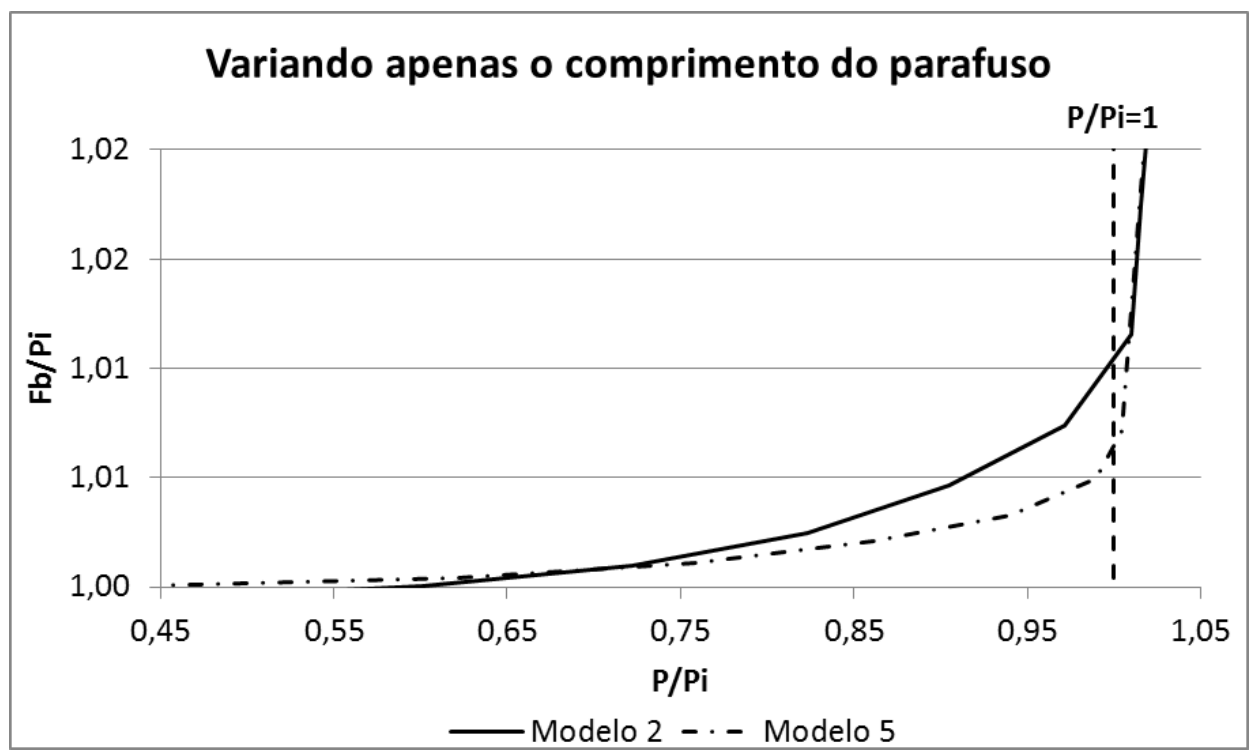

Figura 8 - Carregamentos adimensionais quando da variação apenas do comprimento do parafuso.

Na Figura 9 é observado que quando a carga externa é aplicada mais próxima ao eixo de simetria da junta há uma pequena transmissão de carga desde o primeiro momento da aplicação da carga externa. Tal fenômeno ocorreu somente no modelo 6 . Além disso, é notado que para o carregamento externo próximo à região 
de início de transmissão de carga, o comportamento mecânico para ambos os modelos é semelhante. Entretanto, o modelo com carregamento mais próximo do eixo de simetria absorve menor parcela da carga externa para carregamentos próximos à separação da junta. Tal comportamento dual pode explicar as controvérsias existentes na literatura sobre o efeito da posição de aplicação da carga externa. Por um lado, autores afirmam que o comportamento mecânico da junta é independente da posição de aplicação da carga [8]. Por outro lado, estudo observou que a rigidez global da junta diminui com o aumento da distância de aplicação da carga externa, ou seja, para carregamentos mais próximos ao eixo de simetria, uma maior parcela da carga será absorvida [5]. Além disso, a norma VDI 2230 [2] introduz um parâmetro (n) para o cálculo da porção de carga absorvida pelo parafuso que segue a mesma relação apresentada por Pedersen e Pedersen [5].

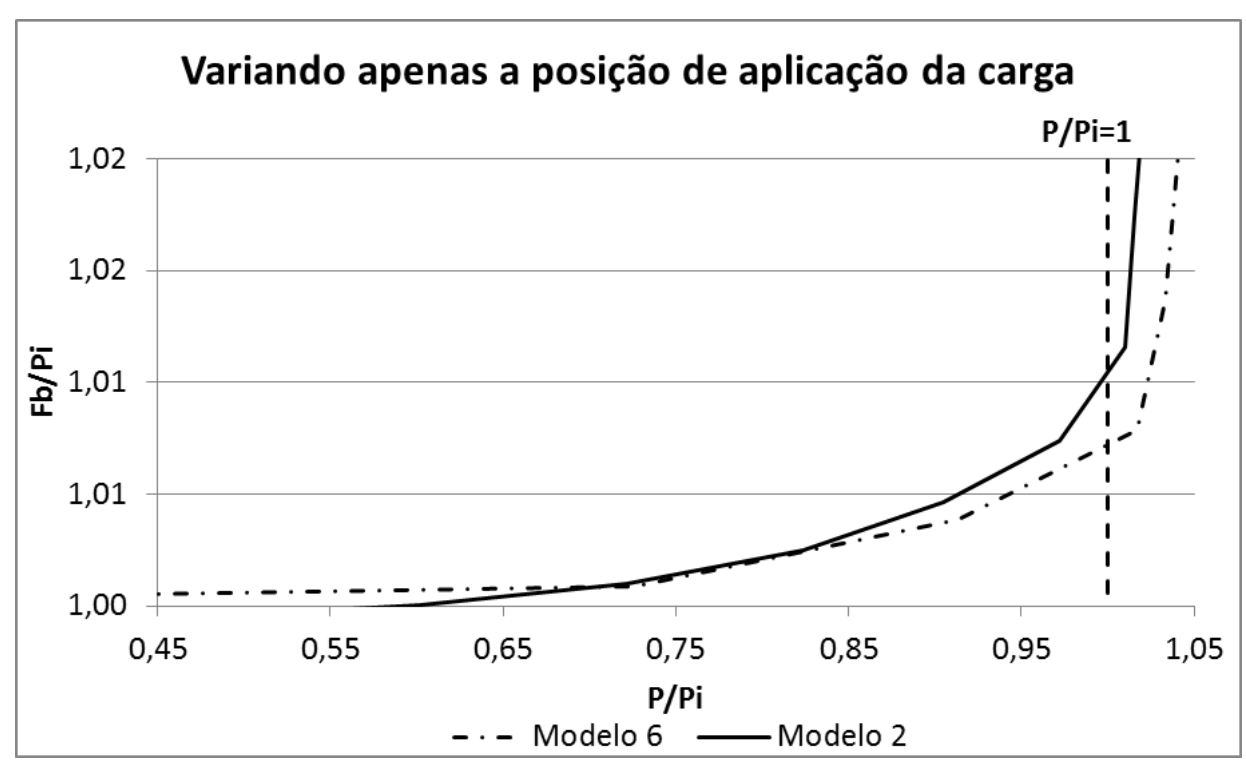

Figura 9 - Carregamentos adimensionais quando da variação apenas da posição da aplicação da carga externa.

Por fim, a figura 10 indica que o parafuso absorve uma maior parcela do carregamento externo quanto menor for o nível de pré-carga. Além disso, outro efeito importante provocado pela variação da pré-carga pode ser observado no gráfico do comportamento mecânico em função dos parâmetros dimensionais (Figura 11): o aumento do nível de pré-carga posterga o início de transmissão de carga e da separação da junta. Isso significa que para junta pré-carregada com menor intensidade, o parafuso experimentará uma parcela da carga para níveis menores de carga externa. Tal fato pode ser comprovado pelos resultados obtidos na literatura [3], que indicam que a carga externa limite de fadiga é maior quanto maior for a pré-carga. 


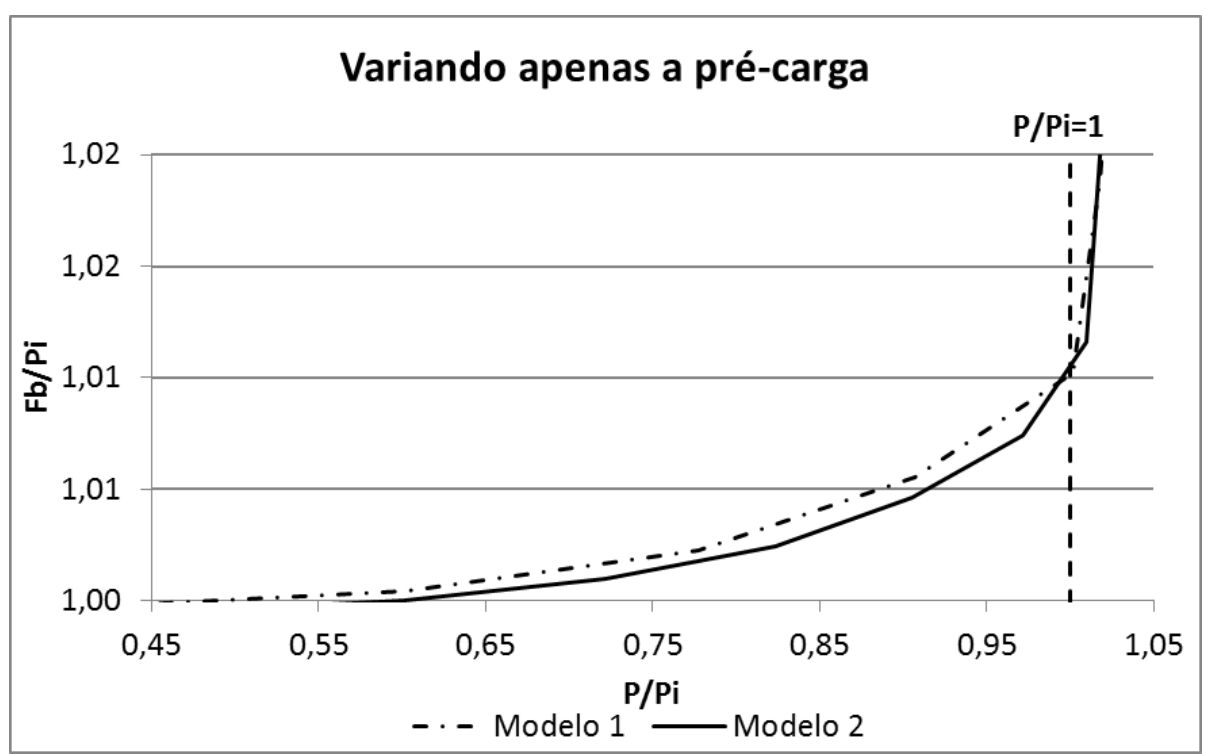

Figura 10 - Carregamentos adimensionais quando da variação apenas da pré-carga.

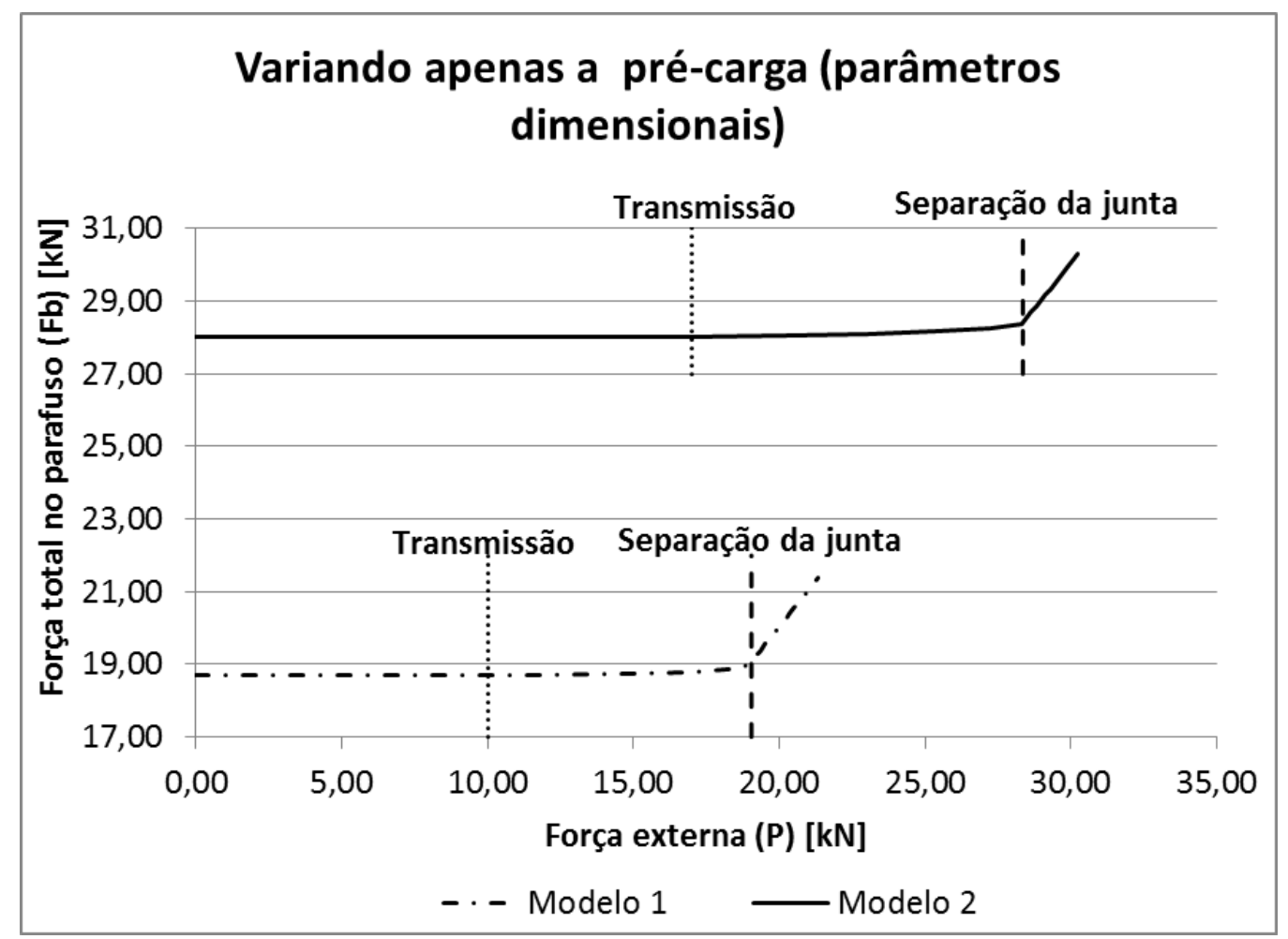

Figura 11 - Carregamentos dimensionais quando da variação apenas da pré-carga.

\section{CONCLUSÃO}

A partir da observação do comportamento mecânico de juntas parafusadas proposto no presente estudo, pôde-se introduzir o conceito de região de não transmissão de carga externa. Esse fenômeno colabora para o entendimento da influência de dois aspectos característicos das juntas parafusadas: limite de resistência à fadiga e a pré-carga.

Além disso, também foi possível evoluir na compreensão dos efeitos da variação de parâmetros de juntas parafusadas em seus comportamentos mecânicos:

- O atrito entre os componentes não altera o comportamento mecânico; 
- Membros em materiais com maior módulo de elasticidade transmitem uma menor parcela da carga ao parafuso para uma mesma carga externa;

- Juntas com parafuso de maior comprimento transmitem uma menor parcela da carga ao parafuso para uma mesma carga externa;

- A posição de aplicação da carga externa gera efeitos característicos: transmissão de carga desde o primeiro momento de aplicação de carga externa, e carga absorvida no parafuso menor para carregamentos próximos a separação da junta;

- A pré-carga possui uma função importante no comportamento da junta: postergar a região de transmissão de carga e a separação da junta.

\section{Agradecimentos}

CAPES, CNPq, FINEP, FAPITEC.

\section{REFERÊNCIAS}

1 Budynas RG, Nisbett JK. Shigley's Mechanical Engineering Design. New York: McGraw-Hill; 2011.

2 VDI 2230. Systematic calculation of high duty bolted joints - Joints with one cylindrical bolt, Part 1; 2014.

3 Griza S. Efeito do torque na vida em fadiga de uniões parafusadas [dissertação de mestrado]. Porto Alegre: UFRGS; 2000.

4 Williams JG, Anley RE, Nash DH, et al. Analysis of externally loaded bolted joints: Analytical, computational and experimental study. International Journal of Pressure Vessels and Piping. 2009; 86:420-427.

5 Pedersen NL, Pedersen P. Bolt-plate contact assemblies with prestress and external loads: Solved with super element technique. Computers and Structures. 2009; 87:1374-1383.

6 Griza S, Da Silva MEG, Santos SV, Strohaecker TR. Experimental evaluation of cyclic stresses on axially loaded bolted joints. Journal of Mechanical Engineering Science. 2015; 230: 2611-2622.

7 Alkatan F, Stephan P, Daidie A, et al. Equivalent axial stiffness of various components in bolted joints subjected to axial loading. Finite Elements in Analysis and Design. 2007; 43:589-598.

8 Lehnhoff TF, Bunyard BA. Effects of bolt threads on the stiffness of bolted joints. Journal of Pressure Vessel Technology, ASME. 2001; 123: 161-165.

9 Wileman J, Choudury M, Green I. Computation of Member Stiffness in Bolted Connections. Journal of Mechanical Design. 1991; 133: 432-437.

10 Nassar SA, Yang X, et al. Nonlinear Deformation Behavior of Clamped Bolted Joints Under a Separating Service Load. Journal of Pressure Vessel Technology. 2011.

11 Thompson FF. Estudo de Resistência à Fadiga de Uniões Parafusadas Submetidas à Carga Axial Cíclica em Função do Comprimento do Parafuso [dissertação de mestrado]. São Cristóvão: UFS; 2017.

12 Pizzio E. Avaliação da vida em fadiga de uniões parafusadas - Estudo de Caso [dissertação de mestrado]. Porto Alegre: UFRGS; 2005.

13 Griza S, Da Silva MEG, Santos SV, et al. The effect of bolt length in the fatigue strength of M24x3 bolt studs. Engineering Failure Analysis. 2013; 34: 397-406. 